\title{
PENGARUH SUAIAN SINGLE ROW DEEP GROOVE BALL BEARING TERHADAP ROLLING RESISTANCE
}

\author{
The Effect of Single Row Deep Groove Ball Bearing Fit on the Rolling Resistance
}

\author{
Rizqi Abdus Syatar ${ }^{1}$, Franciscus Xaverius Kristianta ${ }^{2}$, Boy Arief Fachri3 \\ ${ }^{1,2,3)}$ Jurusan Teknik Mesin, Fakultas Teknik, Universitas Jember \\ Email : ${ }^{1)}$ rizqisyatar6@gmail.ac.id
}

\begin{abstract}
ABSTRAK
Bearing clearance adalah jumlah dari free ball bearing yang bergerak sebelum instalasi. Bearing clearance sangat berpengaruh terhadap nilai rolling resistance. Semakin besar nilai clearance, semakin kecil nilai rolling resistance-nya. Rolling bearing tahan terhadap ball bearing yang telah dan akan terguling karena gesekan. Pada penelitian ini, tipe bearing yang digunakan adalah $6301 \mathrm{ZZ} \mathrm{C3}$ dan 6301 ZZ C4 dengan kecepatan rotasi sebesar 29 rpm, $310 \mathrm{rpm}, 330 \mathrm{rpm}$, dan diberikan gaya 165 $\mathrm{N}, 175 \mathrm{~N}$, dan $200 \mathrm{~N}$. Uji tes bearing dilakukan secara eksperimen menggunakan peralatan rolling resistance test. Hasil pengujian menunjukkan bahwa bearing dengan tipe $6301 \mathrm{ZZ} \mathrm{C4}$ mempunyai nilai rolling resistance yang lebih kecil sebesar $0.22 \mathrm{~N}$ daripada bearing tipe $6301 \mathrm{ZZ} \mathrm{C3}$. Nilai rolling resistane bearing $6301 \mathrm{ZZ} \mathrm{C3}$ adalah sebesar $1.15 \mathrm{~N}$ dan nilai rolling resistance $6301 \mathrm{ZZ} \mathrm{C4}$ adalah $0.93 \mathrm{~N}$.
\end{abstract}

Kata Kunci: internal clearance bearing, bearing, rolling resistance, alat uji rolling resistance.

\begin{abstract}
Bearing clearance is the number of free ball bearing movements before installation. Bearing clearance is very influential on rolling resistance values. The greater the clearance value, the smaller the rolling resistance value. Rolling bearings are resistance to ball bearings that will and have been rolled due to friction. This study uses bearing types $6301 \mathrm{ZZ} \mathrm{C3}$ and $6301 \mathrm{ZZ} \mathrm{C4}$ with rotational speeds of $290 \mathrm{rpm}, 310 \mathrm{rpm}, 330 \mathrm{rpm}$, and given a load of $165 \mathrm{~N}, 175 \mathrm{~N}, 200 \mathrm{~N}$. Bearing testing is carried out experimentally using rolling resistance test equipment. The test results found that bearing with type $6301 \mathrm{ZZ} \mathrm{C4} \mathrm{has} \mathrm{a} \mathrm{smaller} \mathrm{rolling} \mathrm{resistance} \mathrm{value} \mathrm{of} 0.22 \mathrm{~N}$ than bearing type $6301 \mathrm{ZZ} \mathrm{C3.}$ The rolling resistance value of the $6301 \mathrm{ZZ} \mathrm{C3}$ bearing is $1.15 \mathrm{~N}$ and the rolling resistance value of the $6301 \mathrm{ZZ} \mathrm{C4}$ bearing is $0.93 \mathrm{~N}$.
\end{abstract}

Keywords: internal clearance bearing, bearing, rolling resistance, rolling resistance test

\section{PENDAHULUAN}

Kendaraan merupakan peralatan mekanik yang digerakkan oleh peralatan mekanik. Perbedaan kendaraan bermotor dengan motor listrik terletak padasumber energi yang digunakan. Motor listrik menggunakan energi listrik sedangkan kendaraan bermotor menggunakan bahan bakar fosil. Dalam perkembangan saat ini kendaraan tidak hanya dituntut memiliki peforma yang bagus tetapi juga harus mampu menggunakan energi yang sedikit dan bisa digunakan untuk perjalanan yang cukup jauh.

Efisiensi kendaraan dipengaruhi oleh beberapa faktor antara lain berat kendaraan, rolling resistance, dan aerodynamic resistance. Selain ketiga faktor tersebut ada faktor lain yang mempengaruhi efisiensi kendaraan yaitu sistem transmisi, ban, bearing, mesin kendaraan dan kebiasaan mengemudi. Bobot pada kendaraan mempengaruhi tingkat konsumsi energi, rolling resistance juga berdampak terhadap tingkat konsumsi energi. Nilai rolling resistance dipengaruhi oleh komponen yang berputar pada kendaraan salah satunya adalah bearing [2].

Bearing adalah salah satu elemen mesin yang meumpu poros berbeban sehingga dapat berputar secara halus, aman dan berumur panjang [4]. Single row deep groove ball bearing merupakan salah satu jenis bearing yang paling banyak digunakan karena 
keserbaguaannya yang mampu menahan beban radial dan beban aksial [3].

Salah satu faktor yang mempengaruhi rolling resistance adalah tipe bearing. Tipe bearing dipengaruhi oleh jenis ball bearing yang dipakai dan luasan kontaknya [5]. Tipe suaian bearing juga mempengaruhi nilai rolling reistance.

Dengan adanya permasalahan tersebut maka perlu dilakukan penelitian yang lebih mendalam tentang pengaruh bearing terhadap nilai rolling resistance.

\section{METODE PENELITIAN}

Penelitian menggunakan metode ekperimental menggunakan alat uji rolling resistance. Bearing diuji dengan dilakukan pembebanan $165 \mathrm{~N}, 175 \mathrm{~N}, 200 \mathrm{~N}$ dan diputar pada kecepatan 290 rpm, 310 rpm, 330 rpm.

Spesifikasi bantalan yang digunakan seperti yang ditunjukkan Tabel 1.

Tabel 1. Spesifikasi bearing

\begin{tabular}{|c|c|c|c|c|c|}
\hline \multirow[b]{2}{*}{ Kode bearing } & \multicolumn{2}{|c|}{ Diameter } & \multirow{2}{*}{$\begin{array}{l}\text { Tebal } \\
(\mathrm{mm})\end{array}$} & \multirow{2}{*}{$\begin{array}{c}\text { Clearance } \\
\text { (um) }\end{array}$} & \multirow[b]{2}{*}{$\begin{array}{c}\text { Berat } \\
(\mathrm{g})\end{array}$} \\
\hline & $\begin{array}{l}\text { Inner } \\
\text { (mm) }\end{array}$ & $\begin{array}{l}\text { Outer } \\
(\mathrm{mm})\end{array}$ & & & \\
\hline $6301 \mathrm{ZZC} 3$ & 12 & 37 & 12 & $11 \cdot 25$ & 60 \\
\hline $6301 \mathrm{ZZC4}$ & 12 & 37 & 12 & $18 \cdot 33$ & 60 \\
\hline
\end{tabular}

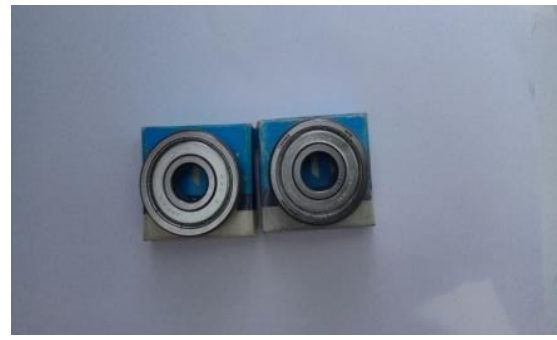

Gambar 1. Bearing

Spesifikasi untuk setiap suaian pada bearing ditunjukkan oleh Tabel 2 dan Gambar 2.
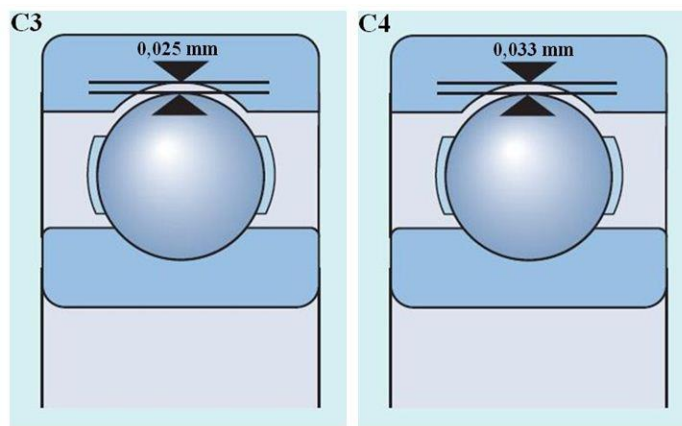

Gambar 2. Letak suaian bearing
Tabel 2. Spesifikasi untuk setiap suaian bearing

\begin{tabular}{|c|c|c|c|c|c|c|c|c|c|c|c|}
\hline \multicolumn{2}{|c|}{ Bore diameter } & \multicolumn{10}{|c|}{ Radial intermal clearance } \\
\hline & s & $\begin{array}{l}\mathrm{C} 2 \\
\text { min. }\end{array}$ & $\max$. & $\begin{array}{l}\text { Normal } \\
\text { min. }\end{array}$ & $\max$. & $\begin{array}{l}C_{3} \\
\min .\end{array}$ & $\max$. & $\begin{array}{l}C_{4} \\
\text { min. }\end{array}$ & $\max$. & $\begin{array}{l}\mathrm{C5} \\
\mathrm{min} .\end{array}$ & $\max$. \\
\hline \multicolumn{2}{|l|}{$\mathrm{mm}$} & \multicolumn{10}{|l|}{$\mu \mathrm{m}$} \\
\hline 2,5 & 6 & 0 & 7 & 2 & 13 & 8 & 23 & - & $-\bar{n}$ & - & - \\
\hline 6 & 10 & 0 & 7 & 2 & 13 & 8 & 23 & 14 & 29 & 20 & 37 \\
\hline 10 & 18 & 0 & 9 & 3 & 18 & 11 & 25 & 18 & 33 & 25 & 45 \\
\hline 18 & 24 & 0 & 10 & 5 & 20 & 13 & 28 & 20 & 36 & 28 & 48 \\
\hline 24 & 30 & 1 & 11 & 5 & 20 & 13 & 28 & 23 & 41 & 30 & 53 \\
\hline 30 & 40 & 1 & 11 & 6 & 20 & 15 & 33 & 28 & 46 & 40 & 64 \\
\hline 40 & 50 & 1 & 11 & 6 & 23 & 18 & 36 & 30 & 51 & 45 & 73 \\
\hline 50 & 65 & 1 & 15 & 8 & 28 & 23 & 43 & 38 & 61 & 55 & 90 \\
\hline 65 & 80 & 1 & 15 & 10 & 30 & 25 & 51 & 46 & 71 & 65 & 105 \\
\hline 80 & 100 & $\frac{1}{2}$ & 18 & 12 & 36 & 30 & 58 & 53 & 84 & 75 & 120 \\
\hline $\begin{array}{l}100 \\
120\end{array}$ & $\begin{array}{l}120 \\
140\end{array}$ & 2 & $\begin{array}{l}20 \\
23\end{array}$ & $\begin{array}{l}15 \\
18\end{array}$ & $\begin{array}{l}41 \\
48\end{array}$ & $\begin{array}{l}36 \\
41\end{array}$ & $\begin{array}{l}66 \\
81\end{array}$ & $\begin{array}{l}61 \\
71\end{array}$ & $\begin{array}{l}97 \\
114\end{array}$ & $\begin{array}{l}90 \\
105\end{array}$ & $\begin{array}{l}140 \\
160\end{array}$ \\
\hline 140 & 160 & 2 & 23 & 18 & 53 & 46 & 91 & 81 & 130 & 120 & 180 \\
\hline 160 & 180 & 2 & 25 & 20 & 61 & 53 & 102 & 91 & 147 & 135 & 200 \\
\hline 180 & 200 & 2 & 30 & 25 & 71 & 63 & 117 & 107 & 163 & 150 & 230 \\
\hline 200 & 225 & 2 & 35 & 25 & 85 & 75 & 140 & 125 & 195 & 175 & 265 \\
\hline 225 & 250 & 2 & 40 & 30 & 95 & 85 & 160 & 145 & 225 & 205 & 300 \\
\hline 250 & 280 & 2 & 45 & 35 & 105 & 90 & 170 & 155 & 245 & 225 & 340 \\
\hline 280 & 315 & 2 & 55 & 40 & 115 & 100 & 190 & 175 & 270 & 245 & 370 \\
\hline 315 & 355 & 3 & 60 & 45 & 125 & 110 & 210 & 195 & 300 & 275 & 410 \\
\hline 355 & 400 & 3 & 70 & 55 & 145 & 130 & 240 & 225 & 340 & 315 & 460 \\
\hline 400 & 450 & 3 & 80 & 60 & 170 & 150 & 270 & 250 & 380 & 350 & 520 \\
\hline 450 & 500 & 3 & 90 & 70 & 190 & 170 & 300 & 280 & 420 & 390 & 570 \\
\hline 500 & 560 & 10 & 100 & 80 & 210 & 190 & 330 & 310 & 470 & 440 & 630 \\
\hline 560 & 630 & 10 & 110 & 90 & 230 & 210 & 360 & 340 & 520 & 490 & 700 \\
\hline 630 & 710 & 20 & 130 & 110 & 260 & 240 & 400 & 380 & 570 & 540 & 780 \\
\hline 710 & 800 & 20 & 140 & 120 & 290 & 270 & 450 & 430 & 630 & 600 & 860 \\
\hline & 900 & 20 & 160 & 140 & 320 & 300 & 500 & 480 & 700 & 670 & 960 \\
\hline 900 & 1000 & 20 & 170 & 150 & 350 & 330 & 550 & 530 & 770 & 740 & 1040 \\
\hline 1000 & 1120 & 20 & 180 & 160 & 380 & 360 & 600 & 580 & 850 & 820 & 1150 \\
\hline 1120 & 1250 & 20 & 190 & 170 & 410 & 390 & 650 & 630 & 920 & 890 & 1260 \\
\hline 1250 & 1400 & 30 & 200 & 190 & 440 & 420 & 700 & 680 & 1000 & - & - \\
\hline 1400 & 1600 & 30 & 210 & 210 & 470 & 450 & 750 & 730 & 1060 & - & - \\
\hline
\end{tabular}

Data dari pengujian kemudian dilakukan perhitungan dengan rumus:

1. Menghitung kecepatan sudut $(\omega)$

$$
\omega=\frac{2 \pi n}{60}
$$

2. Menghitung koefisien rolling resistance

$$
\mathrm{C}_{\mathrm{r}}=\frac{1}{2} \cdot \frac{\left(R_{1}^{2}+R_{2}^{2}\right) d \omega}{g \cdot R_{D} \cdot d t}
$$

3. Menghitung nilai rolling resistance

$$
\mathrm{F}_{\mathrm{r}}=\mathrm{C}_{\mathrm{r}} . \mathrm{W}
$$

\section{HASIL DAN PEMBAHASAN}

\section{Hasil Pengujian Dengan Beban 165 N}

Hasil pengujian beban $165 \mathrm{~N}$ ditunjukkan oleh Grafik 1.

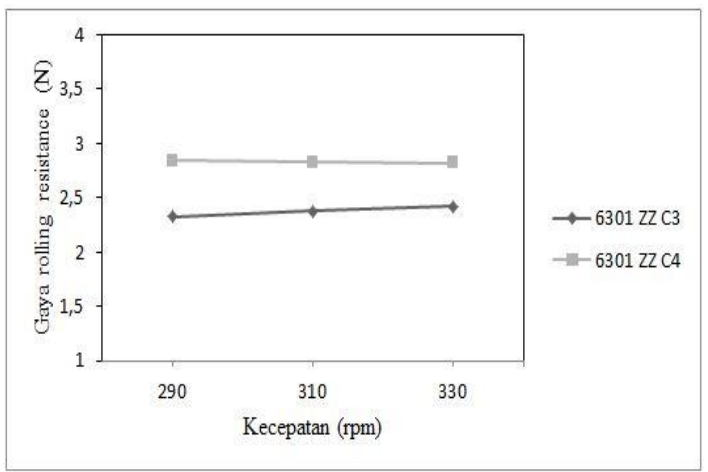

Grafik 1. Hasil pengujian beban $165 \mathrm{~N}$ 


\section{Hasil Pengujian Dengan Beban 175 N}

Hasil pengujian beban $175 \mathrm{~N}$ ditunjukkan oleh Grafik 2

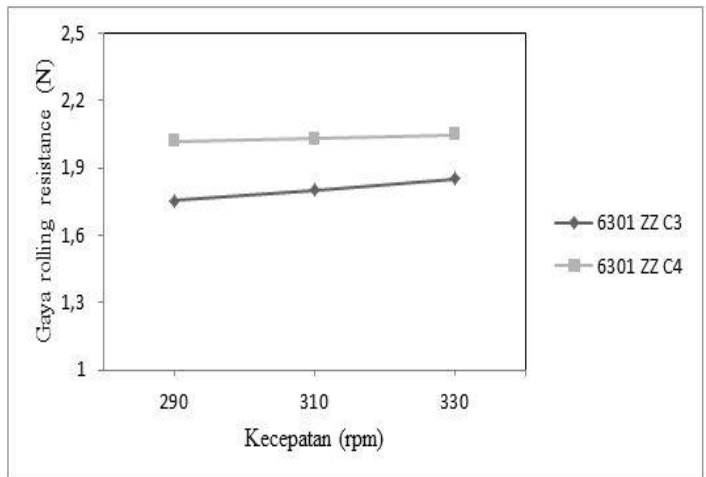

Grafik 2. Hasil pengujian beban $175 \mathrm{~N}$

\section{Hasil Pengujian Dengan Beban 200 N}

Hasil pengujian beban $200 \mathrm{~N}$ ditunjukkan oleh Grafik 3

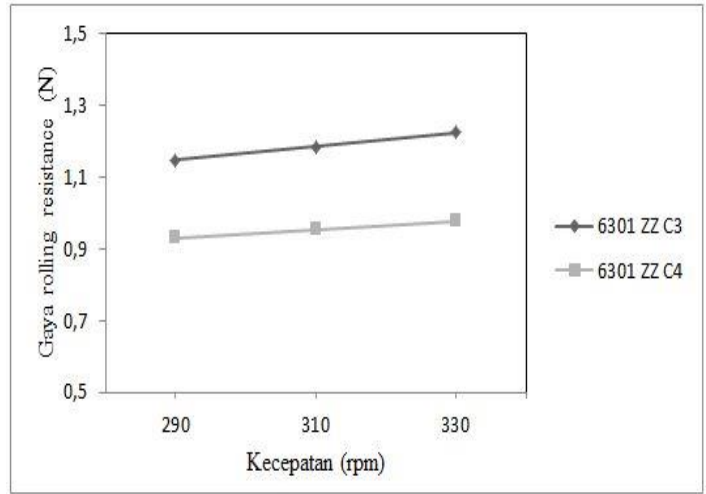

Grafik 3. Hasil pengujian beban $200 \mathrm{~N}$

Hasil Pengujian Dengan Kecepatan 290 rpm

Hasil pengujian beban $290 \mathrm{rpm}$ ditunjukkan oleh Grafik 4.

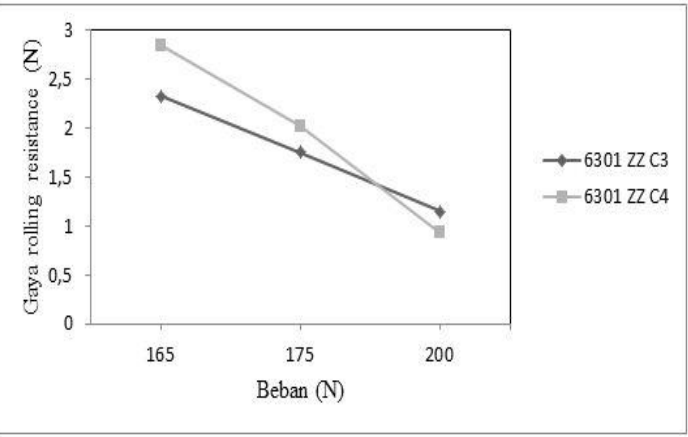

Grafik 4. Hasil pengujian kecepatan 290 rpm

\section{Hasil Pengujian Dengan Kecepatan 310 rpm} Grafik 5.

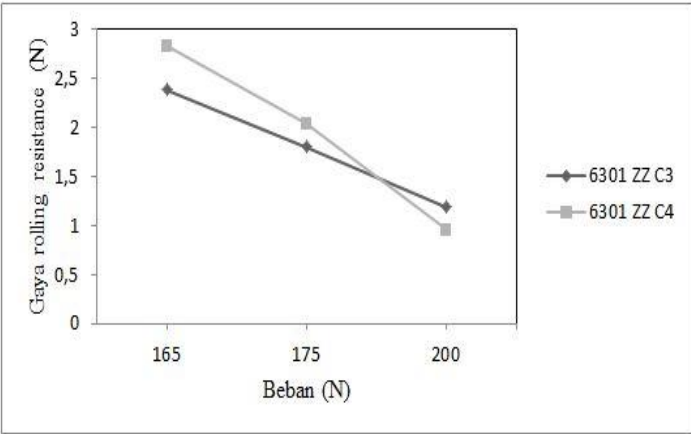

Grafik 5. Hasil pengujian kecepatan 310 rpm

\section{Hasil Pengujian Dengan Kecepatan 330 rpm}

Hasil pengujian beban $330 \mathrm{rpm}$ ditunjukkan oleh Grafik 6

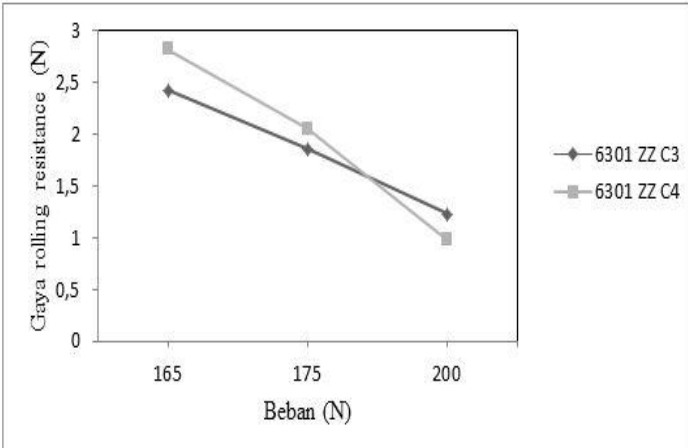

Grafik 6. Hasil pengujian kecepatan 330 rpm

\section{Pengaruh Clearance terhadap Rolling Resistance}

Hasil yang didapatkan dari pengujian antara bearing dengan suaian $\mathrm{C} 3$ dan $\mathrm{C} 4$ adalah bearing dengan suaian $\mathrm{C} 4$ memiliki nilai rolling resistanc terkecil ditunjukkan pada Grafik 7.

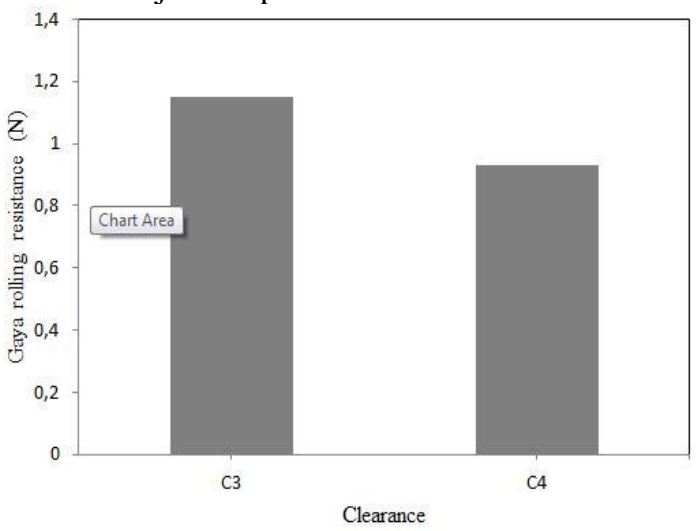

Grafik 7. Rolling resistance C3 dan C4

Bearing 6301 ZZ C4 memiliki nilai rolling resistance paling kecil hal ini disebabkan momen inersianya lebih besar dibandingkan momen inersia pada bearing $6301 \mathrm{ZZ} \mathrm{C3.} \mathrm{Jika} \mathrm{momen} \mathrm{inesia} \mathrm{yang}$ bekerja pada suatu benda, maka benda akan sulit 
berputar saat keadaan diam dan akan sulit berhenti saat keadaan berputar [1].

\section{KESIMPULAN}

Besarnya suaian bearing berpengaruh terhadap nilai rolling resistance. Jika suaian pada bearing semakin besar maka nilai rolling resistance akan semakin kecil. Dari hasil pengujian yang telah dilakukan tipe suaian $\mathrm{C} 4$ memiliki nilai rolling resistance lebih kecil 0,22 $\mathrm{N}$ dibandingkan suaian $\mathrm{C} 3$. Nilai rolling resistance pada suaian $\mathrm{C} 4$ sebesar $0,93 \mathrm{~N}$ dan pada suaian $\mathrm{C} 3$ sebesar $1,15 \mathrm{~N}$.

\section{SARAN}

Penelitaian ini hanya mengambil tipe suaian, masih banyak faktor lain seperti getaran, umur pakai, material bearing, tipe bearing, jenis pelumasan, getaran, dll. Penelitian berikutnya diharapkan meneliti tentang faktor lain yang mempengaruhi nilai rolling resistance.

\section{DAFTAR PUSTAKA}

[1] Chusni, M. M. 2018. Penentuan momen inersia benda silinder pejal dengan integral dan tracker.

[2] Juahala, M. 2014. Improving Vechile Rolling Resistance and Aerodynamics. Alternative Fuels and Advanced Vechile Technologies for Improved Environmental Performance: 462-475.

[3] SKF. 2018. Railway Technical Handbook. Volume 1, Chapter 4, Page 99-105. Rusia: PUB 42/P2 12788 EN.

[4] Sularso, dan K. Suga. 1997. Dasar Perencanaan dan Pemilihan Elemen Mesin.Jakarta: Pradnya Paramita

[5] Tiwari, M., dan K. Gupita. 2000. Effect of Radial Internal Clearance of a Ball Bearing on the Dynamics of a Balanced Horizontal Rotor. Journal of Sound and Vibration. 283(5), 723-756. 